\title{
Preventing university dropout: the relation between the student vulnerability features and academic performance in the first year
}

\author{
Istrate Marinela ${ }^{1}$, Bănică Alexandru ${ }^{1,2}$, Athes Haralambie ${ }^{1}$
}

${ }^{1}$ Department of Geography,"Alexandru Ioan Cuza" University of Iași, Romania, ${ }^{2}$ Romanian Academy, Iași Branch, Romania.

\begin{abstract}
Educational services that universities offer to bachelor students are nowadays under the siege of numerous challenges, ranging from financial and institutional issues to fast changing labour market demands. Universities are confronting fast changes and uncertainties, being asked for adaptation, flexibility and higher ability to (re)act and find the best solutions. Within this broad context, university dropout is one particular new challenge that is often overlooked by decision makers and even by the teaching staff. Our study focuses on problems faced by the first year bachelor students of the Faculty of Geography and Geology at the oldest university in Romania, "Alexandru Ioan Cuza" University of Iasi, students who have benefitted from support from a program financed by BIRD and World Bank, named Romania Secondary Education Project (ROSE). In order to identify and analyse their academic pathway in the first year of study, we tried to correlate a number of qualitative and quantitative using the analysis of variance (ANOVA). The analysis of the results indicates that the prevention of school drop-out should be approached as a continuous process starting from the early years of education. The adaptability to student life depends on the treatment of these inherited and overlooked disadvantages.
\end{abstract}

Keywords: academic adjustment; university dropout; first-year student experience; ANOVA; retention. 


\section{Introduction}

\subsection{General background}

Students come to university to learn and specialize in a particular field. Even if they achieve their goals, at the end of the three years bachelor studies, they are not efficiently trained to live in a real society, to face competition in the labour market or to take on the specific responsibilities of life as an active young adult. Teachers' work should focus, beyond the traditional teaching activities, on encouraging students' independence, on building confidence in their own strengths, on enhancing the skills that help them in life. Sometimes the antagonism between students' academic and social background and the university rigors can be quite high, leading to problems of adaptation.

The transition from highschool to tertiary education represents a challenging switch in a teenager's life, both socially and study-wise, as it changes the entire approach to learning and interacting with teachers (Tulbure, 2010). The most significant challenges: on a personal level (leaving family, managing the personal budget etc.), on an academic level (moving onto a stage of organized, guided activity, taking notes, team-work, time management, individual study etc.) (Lowe\&Cook, 2003, Briggs et al., 2012, O’She\& Vincent, 2011). Thus, it is not surprising that the student population is drastically reduced throughout the university years, only half of the students being able to graduate (Sava et al., 2015). University dropout, also known as attrition or dismissal, can be connected to the requirements of the institution itself i.e. formal stipulations regarding the minimum number of credit points, attendance and ethical behaviour. It can be also context-bound i.e. financial difficulties, abrupt changes within family relations, moving to a different town, getting a job, new demands in the approach to studying. Last, but not least, they can also be academic being caused by the lack of motivation, incapacity to rise up to a certain level of academic expectation, significant change of priorities, wrong choices, dissatisfaction regarding the whole academic experience, inability to properly manage time and workload etc.(Willcoxson, 2010, Bowles et al., 2014). Academic accomplishment is crucial for the successful development of teenagers within the society. Students who do perform well in school are more capable to handle the transition towards the responsibilities and obligations paired with adulthood and they are better equipped for achieving educational, occupational and economic success (Nimante \& Baranova, 2019).

\section{2. Tackling university dropout in Romania. Case study: ROSE Project}

One of the top priorities in the Romanian higher education, especially after Romania joined the European Union, is to ensure equal access to tertiary education for all highschool education. In accord with the Europa 2020 Strategy and the policies and directives established through the Bologna Process, the major educational objectives include 
guaranteeing the equality of chances in accessing quality schooling and improving the enrolment in tertiary education for students belonging to certain categories with poor representation (RNOE, 2019). In Romania there is a relatively low degree of interest in university studies, and, consequently, the number of university graduates decreased to 24.6 $\%$ in 2018, compared to $26.3 \%$ in 2017, for the age group $30-34$, measured according to the European reference criteria. These figures are significantly lower than the European Union average (40.7\%) as well as the established Romanian national objective of $26.7 \%$, decided through the Europe 2020 Strategy. Student drop-out is a lingering phenomenon due to a combination of factors, among which we can single out social and economic factors as well as imbalances in providing quality education (World Bank, 2015). In the rural areas, where poverty is at its worst and the education quality tends to be the lowest, one in four persons aged between 18 and 24 has left school too early. In contrast, this percentage is $15 \%$ in towns and only $4.2 \%$ in cities. (European Commission, 2019).

Romania Secondary Education Project (ROSE), which focuses on reducing school dropout and improving the transition towards higher education through subsidizing highschools with low performance markers, started in 2015, was later on also implemented in universities with the purpose of reducing dropout in the first university year and to improve students' transition onto the job market. One of the project's beneficiaries is the "AlexandruIoanCuza" University in Iassy, and, within this institution, the Faculty of Geography and Geology, where the sub-project GeoDA (Become a graduate of the Faculty of Geography and Geology in Iassy!) was implemented starting from October 2017. GeoDA targets all first-year students, focusing on certain priority categories, namely students who: come from socially and economically disadvantaged rural areas or lowincome families; suffer from chronic illnesses or disabilities; are orphans (one or both parents) or come from foster homes/ institutional care centres/ orphanages etc.; are of Roma ethnicity; have obtained less than 7 at their admission exam; have graduated from vocational, sports or humanities highschools. GeoDA activities mainly consist in tutoring, guiding and counselling, organizing seminars in order to help students acquire the skills necessary in adjusting to student life.

The article focuses on a multi-layered analysis of quantitative and qualitative indicators that could indicate certain vulnerabilities of students from Geography Department that could make them more prone to abandon their studies during the first year. The purpose was to assess the factors that could affect academic performance and find way to tackle these issues by finding suitable solutions. 


\section{Data and Methods}

Using statistical data gather in the first two university years of GeoDA (2017-2018 and 2018-2019), but also integrating the personal observation of (sub)project's members, as well as other official information obtained from the Statistics Department in the Faculty of Geography and Geology, current approach comprises two different stages as follows:

(1) A descriptive analysis of basic indicators, illustrative for the issue in question, such as dropout rate, students' scores at the end of their first year, the correlation between their baccalaureate grade and their results at the end of the first year;

(2)In order to assess the hypothesis that academic success and the possibility of dropout depend on a series of specific quantitative and qualitative variables, we used the Analysis of Variance method (ANOVA), that employs the principles of linear regression, but unlike the latter, it also includes qualitative variables, simultaneously comparing the mean values of several samples. Explanatory variables are often called factors. If $p$ is the number of factors, the ANOVA model can be written as follows:

$$
y_{i}=\beta_{0}+\sum_{j=1}^{p} \beta_{k(i, j), j}+\varepsilon_{i}
$$

where $y_{i}$ is the value observed for the dependent variable for observation $i, k(i, j)$ is the index of the category of factor $\mathrm{j}$ for observation $\mathrm{i}$, and $\varepsilon_{\mathrm{i}}$ is the error of the model. The dependent variable is continuous and it is the score obtained by students at the end of the first year of studies.

The following independent variables were taken into consideration in order to perform ANOVA analysis:3 quantitative variables -baccalaureate score $(B A C C)$, the score for the optional subject for baccalaureate (that is geography, in many cases) (DISC),final admission grade (ADMISS);7 qualitative variables -overall baccalaureate grades lower than/equal to $(B A C C \leq 7)$,students coming from low income families $\left(L O W_{-} I N C\right)$,students coming from rural areas (RURAL), students suffering from disabilities or chronic diseases $(D I S A B)$,students coming from single parent households or orphans (SPO),students coming from foster homes, orphanages or other similar social care institutions (INST),students graduated from highschool specialized in sports, vocational skills or humanities/philological profile ( $S V P)$. By applying ANOVA, the analysis converged towards designing a "model for success" which is a weighted sum of the above mentioned indicators. 


\section{Results and discussions}

\subsection{ROSE GeoDA outcomes - basic statistics}

As far as the dropout in the first year is concerned, in the case of the Faculty of Geography and Geology we can observe (Figure 1a) the fact that in the last years the dropout rate varies around $20 \%$, with a spike in $2014-2015$ and a tendency to decrease in the last 2 years. In absolute figures, however, the decrease in the number of students leaving school is connected to the decrease in the actual number of students. In its first year of implementation (2017 - 2018), 63 students dropped out (from a total of 310), that means $20.39 \%$ of all students enrolled. From the 63 only 13 were members of the target group included in GeoDA (20.63\% of all dropout cases). In its second year, $2018-2019,50$ students dropped out (from a total of 285), meaning $17.54 \%$ of all students enrolled, from which 13 students belonging to the GeoDA target group (26\%). The situation improved, in absolute values, but in relatives terms the impact of the program was not as big as expected. The influence of the activities in the GeoDA sub-project is highlighted when we comparatively analyse students' results after each exam session - on the one hand, students who were part of the GeoDA support group, and, on the other hand, students who were not included in these activities (Figure 1b).

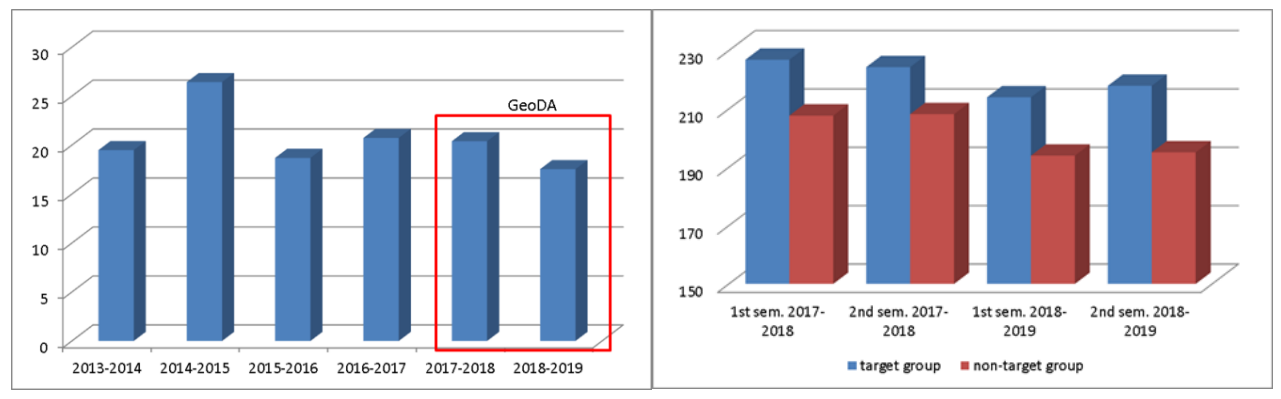

Figure 1. (a, left): Dropout rate (\%) after the first year at the Faculty of Geography and Geology, UAIC, Iasi; (b, right): Average scores obtained by first year students, according to whether they were included or not in GeoDA activities (maximum score per semester $=300$ ).

Analysing the data on baccalaureate results and the final score at the end of the first year of high education for the target grout, and taking into account a maximum score of 600 , one can notice that there is a relatively strong positive correlation(0.228) (Figure 2). 


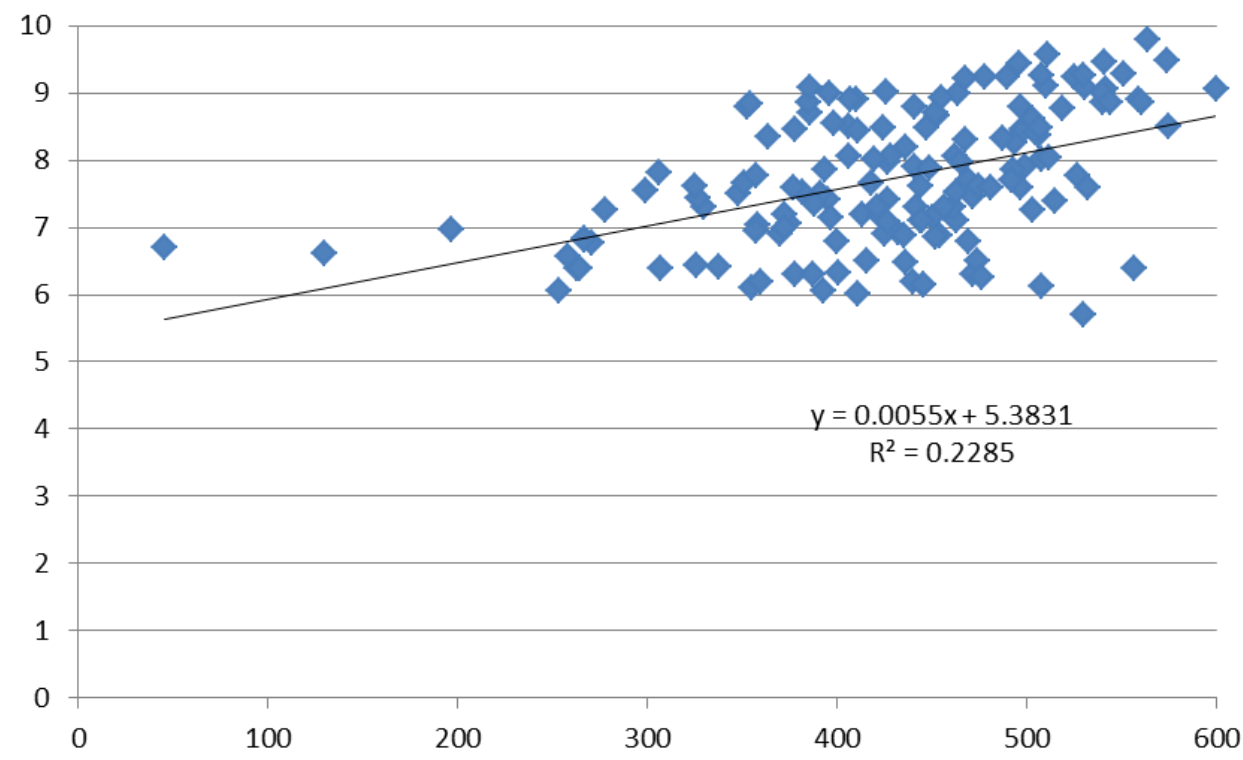

Figure2. Correlation between baccalaureate results - final score at the end of 2018-2019 university year

\subsection{ANOVA Analysis}

In order to integrate a larger number of both quantitative and qualitative factors, the ANOVA method was applied. Analysing the correlation matrix resulted from ANOVA (Figure 3) one can notice that the good results at the end of the first year of study are not directly influenced by the students' social background, various disabilities, chronic diseases or family issues (single parent families or students who are orphans). Being the resident of rural areas does not seem to be an issues for the lack of academic performance, as, by contrary the students from urban environment perform slightly worse than whose from the countryside. More importance lies in the family income and the type of highschool they graduated. Students with sports, arts or theological background (and, to a lesser extent, those specialised in philology) tend to have poorer results, as a sign that a focus on vocational skills or humanities in highschool may alter students' ability to cope with the requirements of a field of study focusing on (Earth) sciences. 


\begin{tabular}{|c|c|c|c|c|c|c|c|c|c|c|c|}
\hline Var_no & Variables & 1 & 2 & 3 & 4 & 5 & 6 & 7 & 8 & 9 & 10 \\
\hline 1 & BACC & & & & & & & & & & \\
\hline 2 & DISC & 0.75 & & & & & & & & & \\
\hline 3 & ADMISS & 0.93 & 0.93 & & & & & & & & \\
\hline 4 & BACC $\leq 7$ & -0.77 & -0.66 & -0.77 & & & & & & & \\
\hline 5 & LOW_INC & 0.22 & 0.20 & 0.23 & -0.18 & & & & & & \\
\hline 6 & RURAL & 0.01 & 0.09 & 0.05 & -0.14 & -0.11 & & & & & \\
\hline 7 & DISAB & -0.06 & -0.04 & -0.05 & 0.12 & 0.04 & -0.11 & & & & \\
\hline 8 & SPO & 0.23 & 0.18 & 0.22 & -0.12 & 0.84 & -0.15 & 0.05 & & & \\
\hline 9 & INST & 0.03 & -0.03 & 0.00 & 0.05 & -0.20 & 0.08 & -0.01 & -0.17 & & \\
\hline 10 & SPV & 0.21 & 0.16 & 0.20 & -0.11 & 0.82 & -0.14 & 0.05 & 0.97 & -0.17 & \\
\hline 11 & $\begin{array}{l}\text { total points accumulated } \\
\text { after the first year }\end{array}$ & $\mathbf{0 . 4 3}$ & $\mathbf{0 . 2 6}$ & $\mathbf{0 . 3 7}$ & -0.41 & -0.01 & 0.09 & -0.02 & 0.00 & -0.06 & -0.01 \\
\hline
\end{tabular}

Figure 3. ANalysis Of Variance (ANOVA). Characteristics of target group - correlation matrix.

Nevertheless, the most important factors of the success after the first year of university studies remain the former performance in school (before the admission at the Faculty of Geography and Geology). It is a form of "path dependence" that can be observe in most of the cases: at the end of the first university year the highest scores are made by students that also had high baccalaureate and admission scores, while students with scores under 7 at the baccalaureate are performing the worst in faculty too. However, some students who started the first year with relatively low scores finished it with significantly better ones, a phenomenon explained on two different levels: an individual one (the students improved their motivation, changed their priorities and focused more on academic success) and an institutional one (represented by the effort of the University or remedial programs, such as GeoDA, to provide students with a better study environment and facilitate higher performance). The design of a "model for success" was done based on standardized values of the analysed indicators. Figure 4 illustrate the model of first year academic success. One can notice that prior school performance, expressed as the baccalaureate score, can be a proper indicator of academic success, a low grade potentially pointing towards a certain lack of basic knowledge, which can be difficult to acquire as a university student. The equation of the model (the formula for integrating variables to explain the final score) can be written as following:

SUCC_MOD $=24.04+62.95 *$ BACC $-26.51 *$ DISC $+57.06 *$ BACC $\leq 7+32.08 *$ LOW_INC $20.40 *$ RURAL $-52.58 *$ DISAB $-12.75 * \mathrm{SPO}+131.89 * \mathrm{INST}+20.53 * \mathrm{SPV}$ 


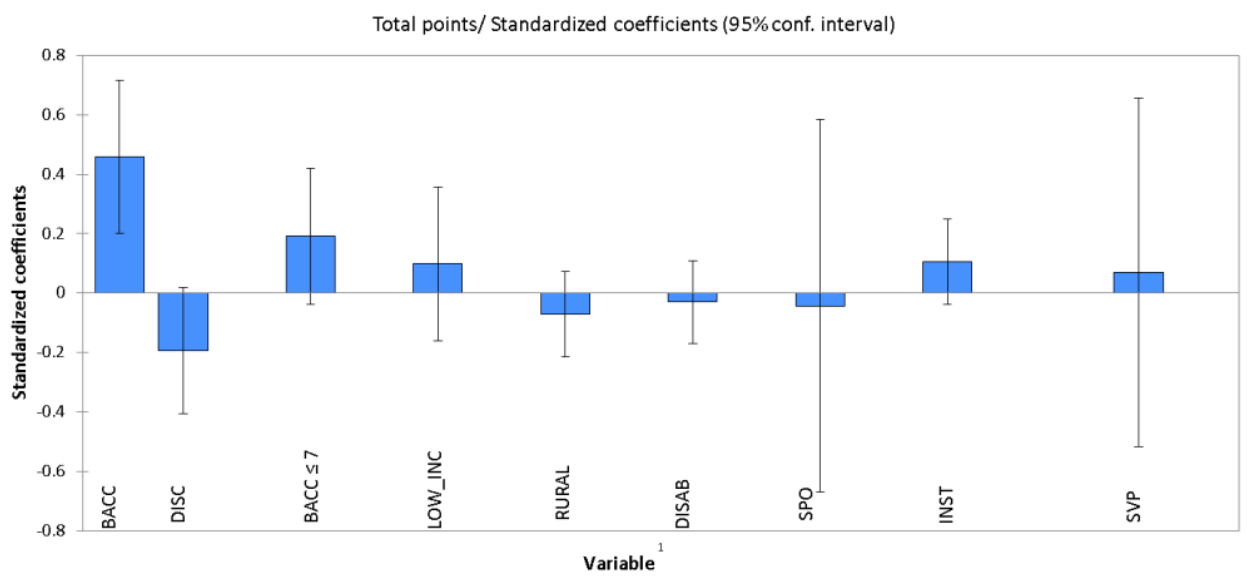

Figure 4. Graphic representation of the weights for the model obtained

\section{Conclusions}

The degree of student retention can be considered as a key and basic performance indicator for higher education systems. The goal should be to have as many students as possible to progress and successfully complete their studies. In the context of expanding participation in higher education, student retention is also a matter of social justice. Overall, highschool students' adaptation to the rigours of university life is influenced by personal but also academic factors. In many cases, the low quality of education provided by highschools acts as a serious obstacle, preventing students from being academically successful. One can notice certain "path dependence" in the evolution of the academic performance of students. Those who entered at the faculty with high scores tend to also have good results at the end of the first year. Being resident in rural areas does not generally create vulnerabilities for the students in the first year, nor the presence of disabilities. Moreover, living with low income in an urban area is worse than having a low income in a rural area, where people have different opportunities of capitalizing on the subsistence agriculture. Nevertheless, the familial incomes continue to have a high influence as well as knowledge and learning abilities gaps accumulated during highschool, especially for those that follower a vocational secondary education. Guidance and support projects, such use as ROSE, are useful, but they tend to display a certain degree of uniformity, stiffness and administrative incoherence that undermines their efficiency. Tutoring and guiding activities are optional, so students cannot be coerced into participation, the structure of the target group does not match the actual group of students at the risk of dropout. 


\section{References}

Briggs A.R.J., Clark J. \&Hall I. (2012). Building bridges: understanding student transition to university. Quality in Higher Education, 18(1), 3-21. doi: 10.1080/13538322.2011.614468

Bowles, A., Fisher, R., McPhail, R., Rosenstreich, D. \& Dobson, A. (2014).Staying the distance: students' perceptions of enablers of transition to higher education.Higher Education Research \& Development, 33(2), 212-225. doi: $10.1080 / 07294360.2013 .832157$

European Commission (2019). Education and Training Monitor 2019. Romania. Retrieved from https://ec.europa.eu/education/sites/education/files/document-library-docs/etmonitor-report-2019-romania_en.pdf

Lowe, H., \& Cook, A. (2003). Mind the Gap: Are students prepared for higher education? Journal of Further and Higher Education, 27(1), 53-76. doi: 10.1080/03098770305629

Nimante, D., \& Baranova, S. (2019). Student Mentoring in the Master Proramme "Pedagogy": the case of University of Latvia. 5th International Conference on Higher Education Advances (HEAd'19), UniversitatPolitecnica de Valencia, pp. 119-126.doi: http://dx.doi.org/10.4995/HEAD19.2019.10279

O'Shea, S. \& Vincent, M. (2011).Uni-Start: a peer-led orientation activity designed for the early and timely engagement of commencing university students. Journal of Continuing Higher Education, 59 (3), 152-160. http://dx.doi.org/10.1080/07377363.2011.614885

Sava, S. Bunoiu, M., Lucheș, D., \&Malița, L. (2015).Adaptation of 1st year students to academic life.Conference Paper. Second National Research Conference in Education at: Iasi, Volume CERED 2015.http://www.cered.ro/2015/volum-conferinta/03

RNOE(Romanian National Office of Education) (2019). Report on the State of Tertiary Education in Romania 2017 - 2018. Retrieved from https://www.edu.ro/sites/default/files/Raport\%20privind\%20starea\%2017\%20-2018.pdf

Tulbure, C. (2010). Determinanţipsihopedagogiciaireuşiteiacademice [Psycho-pedagogical determinants of academic success].ClujNapoca, MA: PresaUniversitarăClujeană

Willcoxson, L. (2010). Factors affecting intention to leave in the first, second and third year of university studies: a semester-by-semester investigation. Higher Education Research \& Development, 29(6), 623-639. doi: 10.1080/07294360.2010.501071

World Bank.(2015). Romania - Secondary Education Project (English). Washington, D.C.: World Bank Group. http://documents.worldbank.org/curated/en/Romania-SecondaryEducation-Project 